\title{
Airway, voice and swallow outcomes following endotracheal intubation and mechanical ventilation for COVID-19 pneumonitis: preliminary results of a prospective cohort study
}

Benjamin Miller ( $\sim$ benjaminmiller@nhs.net)

Guy's and St Thomas' NHS Foundation Trust

Chrysostomos Tornari

Guy's and St Thomas' NHS Foundation Trust

Kelvin Miu

Guy's and St Thomas' NHS Foundation Trust

Andrew Slack

Guy's and St Thomas' NHS Foundation Trust

Patrick Murphy

Guy's and St Thomas' NHS Foundation Trust

Imran Ahmed

Guy's and St Thomas' NHS Foundation Trust

Victoria Burnay

Guy's and St Thomas' NHS Foundation Trust

Asit Arora

Guy's and St Thomas' NHS Foundation Trust

Ricard Simo

Guy's and St Thomas' NHS Foundation Trust

Yakubu Karagama

Guy's and St Thomas' NHS Foundation Trust

\section{Research Article}

Keywords: coronavirus, laryngology, intubation, tracheostomy, airway, dysphonia, dysphagia

Posted Date: August 28th, 2020

DOI: https://doi.org/10.21203/rs.3.rs-65826/v1

License: (c) (1) This work is licensed under a Creative Commons Attribution 4.0 International License.

Read Full License 
Page 2/14 


\section{Abstract}

Introduction: The coronavirus pandemic has resulted in unprecedented rates of patients requiring intubation and ventilation over a short period of time. The authors present 3-month data on airway, voice and swallow outcomes for this cohort to better understand the impact of COVID-19 critical illness on laryngotracheal morbidity.

Methods: An observational cohort study was performed on all patients discharged following critical illness at our tertiary institution over a 2-month period (1 st March 2020 - 30th April 2020). Patients were stratified on the basis of primary diagnosis: COVID-19 pneumonitis, Non-COVID-19 respiratory failure and non-respiratory. Our primary outcome measure was reported airway, voice, and swallow dysfunction during inpatient admission and on 6-12 week Critical Illness Recovery Clinic follow up. Endoscopic findings of patients referred onward to our Multidisciplinary Laryngology-Speech Therapy Clinic were recorded.

Results: 141 patients were included in our study. During inpatient admission there were no statistically significant differences in reported rates of airway, voice, or swallow dysfunction. In Critical IIIness Recovery Clinic, there were markedly higher rates of reported airway, voice and swallow dysfunction in the COVID-19 pneumonitis cohort, although these rates only reached statistical significance in respect to airway outcomes (airway $p=0.038$, voice $p=0.064$, swallow $p=0.240$ ). $100 \%$ of patients reviewed to date in the Laryngology-Speech Therapy Clinic following COVID-19 critical illness had clinically significant laryngeal pathology.

Conclusion: Our data highlights an impending surge in COVID-19 related laryngotracheal morbidity. Robust, prospective screening and clear referral pathways for all patients following COVID-19 critical illness are essential to identifying and managing this cohort.

\section{Introduction}

The first wave of the coronavirus (COVID-19) pandemic has placed exceptional demands on Intensive Care Units (ICU) across the world. As of August 6th 2020, over 18.9 million cases have been reported worldwide with over 710,000 fatalities, and the United Kingdom alone has seen 309,784 confirmed cases, with 13,308 patients requiring ICU admission $[1,2]$.

Laryngeal injury following intubation and mechanical ventilation is a common occurrence with an estimated prevalence of $83 \%$ immediately following extubation [3]. Although a majority of such injuries are trivial and self-limiting, moderate to severe injuries occur in an estimated $13-31 \%$ of patients [3]. Such injuries include laryngotracheal stenosis, vocal cord immobility, ulceration and granulation, and can carry significant morbidity without prompt diagnosis and treatment. Whilst the incidence of post-intubation laryngeal injury in the COVID population remains unknown, early reports have postulated the apparent potential for COVID-19 to predispose to laryngeal oedema, ulceration, and florid laryngotracheitis $[4,5]$. 
Further risk of laryngotracheal injury arises from tracheostomy, required in approximately $8-12 \%$ of patients admitted to modern ICUs for mechanical ventilation [6]. Whilst tracheostomy can reduce the risks of prolonged translaryngeal intubation, sedation and ventilation [7], long-term complications include clinically significant tracheal stenosis (3-12\%), vocal cord immobility, tracheomalacia, granulation, and rarely tracheoesophageal and tracheinomonate fistula [8]. Data are limited regarding the proportion of mechanically ventilated COVID-19 positive patients requiring tracheostomy but preliminary data including that from our own tertiary institution suggests a range between $<10 \%-19.3 \%,[9,10]$. Most published guidelines have recommended late tracheostomy to minimise the risk of disease transmission $[11,12]$.

As many countries emerge from the first wave of the coronavirus pandemic, it is paramount that sufficient attention is given to the longer term recovery of individuals who have been critically ill from COVID-19. Professional and governmental bodies have highlighted the need for comprehensive and holistic follow up [13,14], and from a laryngological standpoint, it is prudent that we anticipate and prepare for an increase in cases of COVID-19 related airway stenosis [15], dysphonia [16] and dysphagia $[17,18]$. Whilst early reports have emerged on inpatient airway, and specifically tracheostomy management outcomes [19], to date there are no published data on COVID-19 intubation related airway, voice, and swallow outcomes.

In this paper we present 3-month data on airway, voice, and swallow outcomes of patients intubated and mechanically ventilated for COVID-19 pneumonitis, as compared against non-COVID-19 respiratory and other emergency intensive care admissions.

\section{Objective}

\section{Method and materials:}

The authors retrospectively collected data on all adult patients discharged from a tertiary care hospital between $1^{\text {st }}$ March 2020 and $30^{\text {th }}$ April 2020 following a period of intubation and mechanical ventilation in the ICU. Data were collected from inpatient electronic patient records, and telemedicine and face-toface follow up clinics.

Baseline demographic and inpatient data included age, gender, ethnicity and APACHE II score. Patients presenting with significant acute head and neck pathology or neurogenic cause of airway, voice, and swallow difficulty were excluded from analysis, as were elective post-operative admissions, and patients who died prior to completing follow up.

Patients were stratified into 3 groups on the basis of primary diagnosis on admission: 1) COVID-19 Pneumonitis, 2) Non-COVID-19 Respiratory Failure 3) Non-Respiratory. Diagnosis of COVID-19 was based on clinical history plus at least one positive swab or subsequent antibody result.

\section{Outcome Measures}


Airway, voice, and swallow outcomes were collected from two data points; hospital admission, and first follow up in our multidisciplinary Critical Illness Recovery Clinic.

During admission we retrospectively analysed via electronic patient records the proportion of cases in which laryngeal injury and airway, voice, and swallowing dysfunction were identified following extubation, and whether these had resolved prior to hospital discharge. We also specifically reviewed Speech and Language Therapy (SLT) assessment outcomes and scope findings where performed.

Patients were prospectively followed up in a multidisciplinary Critical Illness Recovery Clinic at approximately 6-12 weeks following discharge. All patients were screened using the 3-item AirwayDyspnoea, Voice, Swallow (AVS) Scale, completed electronically, in which the individual rates each respective component from 1 (no dysfunction) to 5 (most severe dysfunction) [20,21]. Individuals with abnormal Voice and Swallow scores ( $>1$ in either section) completed the validated Voice Handicap Index10 (VHI-10) and Eating Assessment Tool-10 (EAT-10) respectively. All cases of suspected clinically significant airway, voice, and swallow sequelae were referred onward to joint SLT-Laryngology clinic. In instances where above data were not captured in clinic, the authors conducted further telemedicine consultation for completeness.

To identify risk factors and potential confounders, we analysed whether tracheostomy was performed, technique of tracheostomy and duration, endotracheal (ETT) and tracheostomy tube (TT) sizes, total number and grade of intubations, maximum 6am cuff pressure, and total cuff up duration. Chi-Square, one-way analysis of variance (ANOVA), and Kruskal-Wallis tests for statistical significance between patient group outcomes were additionally performed.

The study was prospectively registered and conducted in accordance with the ethical regulations of our audit approval body (registration number 10897).

\section{Results}

\section{Patient demographics}

Over a 2-month period (March $\left.1^{\text {st }} 2020-A p r i l 30^{\text {th }} 2020\right) 141$ patients were discharged from our institution following emergency ICU admission for intubation and mechanical ventilation. 86 patients were admitted with the primary diagnosis of COVID-19 pneumonitis, 17 patients were admitted with nonCOVID-19 respiratory failure, and 26 patients were admitted with a non-respiratory primary diagnosis. 12 patients did not meet the inclusion criteria and were excluded from data analysis ( 5 acute upper aerodigestive tract pathology, 3 acute neurogenic causes for AVS failure, 1 patient on pre-existing long term ventilation, 3 deceased prior to first follow up). A further 7 patients were excluded from recovery follow up being either unreachable or readmitted at another institution. Patient demographics are outlined in Table 1. A small but statistically significant $(p<0.05)$ difference was noted between cohort age groups. 


\section{ICU admission data}

A summary of relevant ICU airway management data is presented in Table 2. There were small but statistically significant differences in ETT size (larger in non-COVID-19 respiratory failure) and average maximum 6am cuff pressure (higher in COVID-19 pneumonitis) between cohorts.

\section{Inpatient airway, voice, swallow outcomes}

A summary of inpatient airway, voice, and swallow outcomes is presented in Table 3. Similar rates of airway, voice, and swallow abnormalities were reported between the COVID-19 and Non-COVID-19 respiratory failure cohorts (airway $43 \%$ vs $53 \%$, voice, $24 \%$ vs $29 \%$, swallow $31 \%$ vs $42 \%$ ), with lower rates demonstrated in the non-respiratory cohort, although none of these differences achieved statistical significance.

\section{Critical Illness Recovery Clinic: airway, voice, swallow outcomes}

A summary of airway, voice and swallow outcomes on initial Critical Illness Recovery Clinic follow up is presented in Table 4. The COVID-19 cohort demonstrated higher overall rates of self-reported airwaydyspnoea, voice and swallow difficulties (airway $59 \%$ vs $44 \%$ and $31 \%$, voice $40 \%$ vs $19 \%$ and $19 \%$, swallow $21 \%$ vs $6 \%$ and $12 \%$ ). Differences in airway-dyspnoea outcomes were statistically significant, ( $p$ $=0.038)$ whilst voice and swallow outcomes were not $(p=0.064$ and $p=0.240)$. All patients reporting dysphonia or dysphagia completed $\mathrm{VHI}-10$ or EAT-10 questionnaire, with no statistically significant differences between groups.

\section{Laryngology-Speech Therapy Multidisciplinary Clinic: endoscopic findings}

30 patients from the cohort were referred tothe Joint Laryngology-Speech Therapy Multidisciplinary Clinic. A breakdown of the referrals indications is summarised in Table 5, with no statistically significant differences noted between cohorts. To date only 7 post-ICU COVID-19 pneumonitis patients have undergone face to face review, with endoscopy confirming clinically significant laryngotracheal injury in $100 \%$ cases referred. Endoscopic diagnoses thus far have included 1 case of bilateral vocal cord immobility, 1 post-tracheostomy decannulation a-frame deformity with displaced cartilage and granuloma, 1 vocal cord intubation granuloma, 3 cases of posterior glottic scarring, and 1 posterior glottic cyst (Figure 1a-d).

In keeping with ENT UK guidance on minimising disease transmission, follow up has initially been limited to urgent airway cases, although as pandemic restrictions ease a more detailed understanding of airway, voice, and swallow outcomes informed by endoscopic findings will be possible [22]. 


\section{Discussion}

As many countries emerge from the first wave of the coronavirus pandemic, sufficient attention must be afforded to the long term rehabilitation needs and outcomes of patients following their initial critical illness $[13,14]$. Multidisciplinary, protocolised follow up and the use of relevant screening tools have been invaluable to an effective rehabilitation pathway at our institution. All patients admitted to Intensive Care on a non-elective basis were offered follow up, and patients screening positively for clinically suspected airway, voice and swallowing dysfunction were referred onward to the Joint Laryngology-Speech Therapy Multidisciplinary Clinic.

The data presented above constitutes the first reported airway, voice and swallow outcomes for patients following COVID-19 pneumonitis critical illness, offering an important early insight into the relationship between the disease and its laryngotracheal sequelae. A higher proportion of airway, voice, and swallow dysfunction was demonstrated across all measures in the COVID-19 cohort on outpatient follow up, although only the airway-dyspnoea outcomes achieved statistical significance. These findings highlight the importance of proactive, prospective screening for these sequelae, and also gives an indication of the increased COVID-19 related healthcare burden that laryngology and speech and language therapy departments are likely to face in the near future.

A number of factors limit our conclusions regarding the differences in airway, voice and swallow outcome between cohort groups.

The present data contain relatively small non-COVID cohorts, and whilst important to have a comparator, this poses a risk of type I and type II error. The COVID-19 cohort overall attended follow up earlier than the other cohorts, potentially contributing to the higher prevalence of airway, voice and swallow difficulty. Quantitative data is largely limited to patient reported outcome measures from which we have inferred the likelihood of laryngeal injury, although early endoscopic findings appear to corroborate these data. The AVS scale, whilst commonly utilised in laryngology in the United Kingdom is un-validated in adults, and was designed to assess treatment outcomes in confirmed laryngotracheal stenosis with an additional parameter for endoscopic airway findings, absent in this study[20,21]. In absence of endoscopic findings, high airway-dyspnoea scores are likely influenced by the protracted impact of COVID-19 on pulmonary function [. The authors also recognise that the observed differences in follow up voice $(p=0.064)$ and swallow $(p=0.240)$ outcomes did not achieve statistical significant $(p<0.05)$.

As follow up took place in a multidisciplinary intensive care recovery clinic in which patients were required to complete a wide range of other questionnaires, the authors consensus was that the AVS scale was the most pragmatic way to address laryngotracheal symptoms whilst minimising 'questionnaire fatigue' and non-completion.

We have recognised and mitigated for many of these limitations with comprehensive assessment of potential confounders and statistical tests of significance. This preliminary data provides a baseline against which long term (six-month and one-year) follow up is planned, with additional patients recruited 
to the non-COVID arms, and quantitative analysis of endoscopic findings as greater volumes of patients are able to attend the Joint Laryngology-Speech Therapy Multidisciplinary Clinic, with the easing of COVID-19 restrictions. Endoscopic follow up to date suggests high rates persistent laryngotracheal injury concordant with above patient reported outcomes.

\section{Conclusions}

Our results demonstrate that at up to 3 months follow up, patients previously intubated and ventilated in critical care for COVID-19 pneumonitis report higher overall rates of airway, voice, and swallow difficulty compared to non-COVID-19 cohorts. The differences in voice and swallow outcomes were not statistically significant, however, specialist follow up to date suggests high concordance between patient reported symptoms and endoscopic findings.

Robust prospective screening protocols and referral pathways are essential to successfully manage the significant rates of laryngotracheal sequelae that occur following ICU admission for COVID-19 pneumonitis, and longer term follow up complemented by endoscopic assessment is essential to improving patient outcomes.

\section{Declarations}

\section{Funding}

This review received no funding

\section{Conflict of interest / Competing interests}

All authors declare that they have no conflicts of interest

\section{Ethics approval}

The study was prospectively registered and conducted in accordance with the ethical regulations of our audit approval body (registration number 10897). The article does not contain any studies with animals performed by any of the authors.

\section{Consent to participate}

Observational study - NA

\section{Consent for publication}


Written informed consent for publication of non-identifiable endoscopic upper airway images was obtained.

\section{Availability of data and material}

Anonymised data sets available on request

\section{References}

1. Coronavirus Resource Centre. John Hopkins University. Accessed $6^{\text {th }}$ August, 2020. https ://coronavirus.jhu.edu/map.html

2. Intensive Care National Audit \& Research Centre (ICNARC) report on COVID-19 in critical care. Accessed $6^{\text {th }}$ August 2020. https://www.icnarc.org/Our-Audit/Audits/Cmp/Reports

3. Brodsky MB, Levy MJ, Jedlanek E, et al. Laryngeal Injury and Upper Airway Symptoms After Oral Endotracheal Intubation With Mechanical Ventilation During Critical Care: A Systematic Review. Crit Care Med. 2018;46(12):2010-2017.

4. Mcgrath BA, Wallace S, Goswamy J. Laryngeal oedema associated with COVID-19 complicating airway management. Anaesthesia. 2020;75(7):972.

5. Oliver CM, Campbell M, Dulan $O$ et al. Appearance and management of COVID-19 laryngo-tracheitis: two case reports. F1000 Research 2020, 9:310. Accessed on 30 th June 2020. https://doi.org/10.12688/f1000research.23204.1

6. Mehta AB, Syeda SN, Bajpayee L, Cooke CR, Walkey AJ, Wiener RS. Trends in tracheostomy for mechanically ventilated patients in the United States. Am J Respir Crit Care Med 2015; 192: 446-54.

7. Ng FK, Wallace S, Khalil U, McGrath BA. Duration of trans-laryngeal intubation before tracheostomy is associated with laryngeal injury when assessed using FEES. BJA. 2019. Epub. [Online] Accessed $30^{\text {th }}$ June 2020. https://bjanaesthesia.org/article/S0007-0912(19)30412X/pdf

8. Fernandez-bussy S, Mahajan B, Folch E, Caviedes I, Guerrero J, Majid A. Tracheostomy Tube Placement: Early and Late Complications. J Bronchology Interv Pulmonol. 2015;22(4):357-64.

9. Anesi GL. Coronavirus disease 2019 (COVID-19): Critical care and airway management issues. In: UpToDate, Post TW (Ed), UpToDate, Waltham, MA. Accessed on $30^{\text {th }}$ June 2020 https://www.uptodate.com/contents/coronavirus-disease-2019-covid-19-critical-care-and-airwaymanagement-issues

10. Takhar A, Tornari C, Amin N, et al. Percutaneous tracheostomy in COVID-19 pneumonitis patients requiring prolonged mechanical ventilation: Initial experience in 51 patients and preliminary outcomes. Authorea. May 06, 2020. DOI: 10.22541/au.158801954.47538762/v2

11. Takhar A, Walker A, Tricklebank S, et al. Recommendation of a practical guideline for safe tracheostomy during the COVID-19 pandemic. Eur Arch Otorhinolaryngol. 2020;277(8):2173-2184. 
12. Schultz P, Morvan J-B, Fakhry N, Morinière S, Vergez $S$, Lacroix C, et al. French consensus regarding precautions during tracheostomy and post-tracheostomy care in the context of COVID-19 pandemic. Eur Ann Otorhinolaryngol Head Neck Dis. 2020

13. NHS England. After-care needs of inpatients recovering from COVID-19. Accessed $30^{\text {th }}$ June 2020 https://www.england.nhs.uk/coronavirus/wp-content/uploads/sites/52/2020/06/C0388-after-careneeds-of-inpatients-recovering-from-covid-19-5-june-2020-1.pdf

14. Faculty of Intensive Care Medicine. Position statement and provisional guidance: recovery and rehabilitation following the pandemic. Accessed 30 th June 2020. https://www.ficm.ac.uk/sites/default/files/ficm_rehab_provisional_guidance.pdf

15. Piazza C, Filauro M, Dikkers FG, et al. Long-term intubation and high rate of tracheostomy in COVID19 patients might determine an unprecedented increase of airway stenoses: a call to action from the European Laryngological Society. Eur Arch Otorhinolaryngol. 2020;

16. Royal College of Speech and Language Therapy. COVID-19 speech and language therapy rehabilitation pathway. 2020. Accessed on $30^{\text {th }}$ June 2020. https://www.rcslt.org/-/media/rcsltcovid-19-slt-rehab-pathway.pdf

17. Mohan R, Mohapatra B. Shedding Light on Dysphagia Associated With COVID-19: The What and Why. OTO Open. 2020;4(2):2473974X20934770.

18. Frajkova Z, Tedla M, Tedlova E, Suchankova M, Geneid A. Postintubation Dysphagia During COVID19 Outbreak-Contemporary Review. Dysphagia. 2020;

19. Tornari C, Surda P, Takhar A, et al. Tracheostomy, ventilatory wean, and decannulation in COVID-19 patients. Eur Arch Otorhinolaryngol. 2020;

20. Sandhu G, Nouraei R. Laryngeal and Tracheobronchial Stenosis. Plural Publishing, San Diego. 2014

21. Nouraei SA, Nouraei SM, Upile T, Howard DJ, Sandhu GS. A proposed system for documenting the functional outcome of adult laryngotracheal stenosis. Clin Otolaryngol. 2007;32(5):407-9.

22. ENT UK. Guidance for ENT during the COVID-19 pandemic. Accessed on $25^{\text {th }}$ July 2020. https://www.entuk.org/guidance-ent-during-covid-19-pandemic

23. Zhao Y, Shang Y, et al. Follow-up study of the pulmonary function and related physiological characteristics of COVID-19 survivors three months after recovery. EClinicalMedicine, 2020. Accessed on $24^{\text {th }}$ July 2020 . https://doi.org/10.1016/j.eclinm.2020.100463

\section{Tables}

Table 1. Patient demographics. (Median and IQR unless stated) 


\begin{tabular}{|llllll|}
\hline & $\begin{array}{l}\text { COVID-19 } \\
\text { Pneumonitis }\end{array}$ & $\begin{array}{l}\text { Non-COVID-19 Respiratory } \\
\text { Failure }\end{array}$ & $\begin{array}{l}\text { Non- } \\
\text { Respiratory }\end{array}$ & Overall & P \\
Cases & 86 & 17 & 26 & 129 & \\
Age & $52(42-59)$ & $53(43-59)$ & $55(47-73)$ & $\begin{array}{l}51(43- \\
60)\end{array}$ & 0.044 \\
Gender & $56: 30$ & $11: 6$ & $14: 12$ & $82: 48$ & \\
M:F & & & & & \\
$\begin{array}{l}\text { APACHE } \\
\text { II }\end{array}$ & $15(11-18)$ & $19(15-21)$ & $17(14-21)$ & $15(12-$ & 0.087 \\
\hline
\end{tabular}

Table 2. Intubation and tracheostomy data. (Median and IQR unless stated)

\begin{tabular}{|llllll|}
\hline & $\begin{array}{l}\text { COVID-19 } \\
\text { Pneumonitis }\end{array}$ & $\begin{array}{l}\text { Non-COVID-19 } \\
\text { Respiratory Failure }\end{array}$ & $\begin{array}{l}\text { Non- } \\
\text { Respiratory }\end{array}$ & Overall & P \\
\hline CC LOS & $15(9-23)$ & $22(13-37)$ & $15(8-21)$ & $\begin{array}{l}15(9- \\
24)\end{array}$ & 0.289 \\
\hline $\begin{array}{l}\text { Intubation grade } \\
\text { (range) }\end{array}$ & $1(1-4)$ & $1(1-2)$ & $1(1-3)$ & $1(1-4)$ & 0.223 \\
\hline $\begin{array}{l}\text { Number of intubations } \\
\text { (range) }\end{array}$ & $2(1-4)$ & $2(1-4)$ & $1(1-4)$ & $2(1-4)$ & 0.180 \\
\hline $\begin{array}{l}\text { ETT size (range) } \\
\text { Maximum 6am cuff } \\
\text { pressure (mmHg) }\end{array}$ & $8(7-9)$ & $9(7-9)$ & $8(7-9)$ & $8(7-9)$ & 0.009 \\
\hline $\begin{array}{l}\text { Intubation duration } \\
\text { (days) }\end{array}$ & $12(8-18)$ & $12(7-14)$ & $30(27-30)$ & $30(20-$ & $<0.001$ \\
\hline $\begin{array}{l}\text { Tracheostomy (\%) } \\
\text { (3)-35) }\end{array}$ & $35(30 / 86)$ & $47(8 / 17)$ & $6(3-11)$ & $11(5-$ & 0.023 \\
\hline $\begin{array}{l}\text { Tracheostomy tube } \\
\text { size (range) }\end{array}$ & $8(7-9)$ & $8(7-9)$ & $19(5 / 26)$ & 33 & 0.145 \\
\hline $\begin{array}{l}\text { Total cuff up duration } \\
\text { (days) }\end{array}$ & $12(7-30)$ & $15(11-19)$ & $8(7-8)$ & $8(7-9)$ & 0.070 \\
\hline
\end{tabular}


Table 3. Inpatient airway, voice, swallow outcomes

\begin{tabular}{|llllll|}
\hline & $\begin{array}{l}\text { COVID-19 } \\
\text { Pneumonitis }\end{array}$ & $\begin{array}{l}\text { Non-COVID-19 } \\
\text { Respiratory } \\
\text { Failure }\end{array}$ & $\begin{array}{l}\text { Non- } \\
\text { Respiratory }\end{array}$ & Overall & P \\
\hline $\begin{array}{l}\text { Inpatient airway, voice, } \\
\text { swallow abnormalities } \\
\text { identified (\%) }\end{array}$ & $43(37 / 86)$ & $53(9 / 17)$ & $27(7 / 26)$ & $\begin{array}{l}43 \\
(56 / 130)\end{array}$ & 0.194 \\
\hline $\begin{array}{l}\text { Airway concerns reported } \\
\text { (\%) }\end{array}$ & $9(8 / 86)$ & $6(1 / 17)$ & $0(0 / 26)$ & $\begin{array}{l}7 \\
(9 / 130)\end{array}$ & 0.607 \\
\hline Dysphonia reported (\%) & $24(21 / 86)$ & $29(5 / 17)$ & $23(6 / 26)$ & $\begin{array}{l}25 \\
(32 / 130)\end{array}$ & 0.682 \\
\hline Dysphagia reported (\%) & $31(37 / 86)$ & $42(7 / 17)$ & $27(7 / 26)$ & $\begin{array}{l}30 \\
(39 / 130)\end{array}$ & 0.335 \\
\hline
\end{tabular}

Table 4. Outpatient airway, voice, and swallow outcomes 


\begin{tabular}{|llllll|}
\hline & $\begin{array}{l}\text { COVID-19 } \\
\text { Pneumonitis }\end{array}$ & $\begin{array}{l}\text { Non-COVID-19 } \\
\text { Respiratory } \\
\text { Failure }\end{array}$ & $\begin{array}{l}\text { Non- } \\
\text { respiratory }\end{array}$ & Overall & P \\
\hline $\begin{array}{l}\text { Time of follow up, weeks } \\
\text { (days) }\end{array}$ & $6(6-8)$ & $12(9-12)$ & $12(10-12)$ & $8(6-12)$ & $<0.001$ \\
\hline $\begin{array}{l}\text { Recovery Clinic airway, } \\
\text { voice, swallow } \\
\text { abnormalities (\%) }\end{array}$ & $69(55 / 80)$ & $56(9 / 16)$ & 42 & $\begin{array}{l}61 \% \\
(11 / 26)\end{array}$ & 0.049 \\
\hline $\begin{array}{l}\text { Airway-dyspnoea reported } \\
\text { (\%) }\end{array}$ & $59(47 / 80)$ & $44(7 / 16)$ & $31(8 / 26)$ & $\begin{array}{l}51 \\
(64 / 122)\end{array}$ & 0.038 \\
\hline $\begin{array}{l}\text { Dysphonia reported (\%) } \\
\text { Dysphagia reported (\%) }\end{array}$ & $40(32 / 80)$ & $19(3 / 16)$ & $19(5 / 26)$ & 33 & 0.064 \\
\hline $\begin{array}{l}\text { Average Airway score } \\
\text { Average Voice score }\end{array}$ & $21(17 / 80)$ & $6(1 / 16)$ & $12(3 / 26)$ & $\begin{array}{l}17 \\
(21 / 122)\end{array}$ & 0.240 \\
\hline $\begin{array}{l}\text { Average Swallow score } \\
\text { Average VHI-10 (of }\end{array}$ & 1.2 & 1.7 & 1.3 & 1.8 & 0.047 \\
\hline $\begin{array}{l}\text { Avsphonic patients) } \\
\text { dysphagic pat-10 (of }\end{array}$ & 17 & 1.1 & 1.2 & 1.4 & 0.171 \\
\hline
\end{tabular}

Table 5. SLT-Laryngology referrals and indications

\begin{tabular}{|llllll|}
\hline & $\begin{array}{l}\text { COVID-19 } \\
\text { Pneumonitis }\end{array}$ & $\begin{array}{l}\text { Non-COVID-19 } \\
\text { Respiratory Failure }\end{array}$ & $\begin{array}{l}\text { Non- } \\
\text { respiratory }\end{array}$ & Overall & P \\
\hline $\begin{array}{l}\text { Referred for SLT- } \\
\text { Laryngology follow up } \\
(\%)\end{array}$ & $29 \%(23 / 80)$ & $25 \%(4 / 16)$ & $8 \%(2 / 26)$ & $\begin{array}{l}25 \% \\
(30 / 122)\end{array}$ & 0.090 \\
\hline Airway referral (\%) & $5 \%(4 / 80)$ & $6 \%(1 / 16)$ & $0 \%(0 / 26)$ & $\begin{array}{l}5 \% \\
(6 / 122)\end{array}$ & 0.939 \\
\hline Dysphonia referral (\%) & $24 \%(19 / 80)$ & $19 \%(3 / 16)$ & $8 \%(2 / 26)$ & $\begin{array}{l}21 \% \\
(26 / 122)\end{array}$ & 0.201 \\
\hline Dysphagia referral (\%) & $8 \%(6 / 80)$ & $0 \%(0 / 16)$ & $0 \%(0 / 26)$ & $\begin{array}{l}4 \% \\
(5 / 122)\end{array}$ & 0.973 \\
\hline
\end{tabular}




\section{Figures}

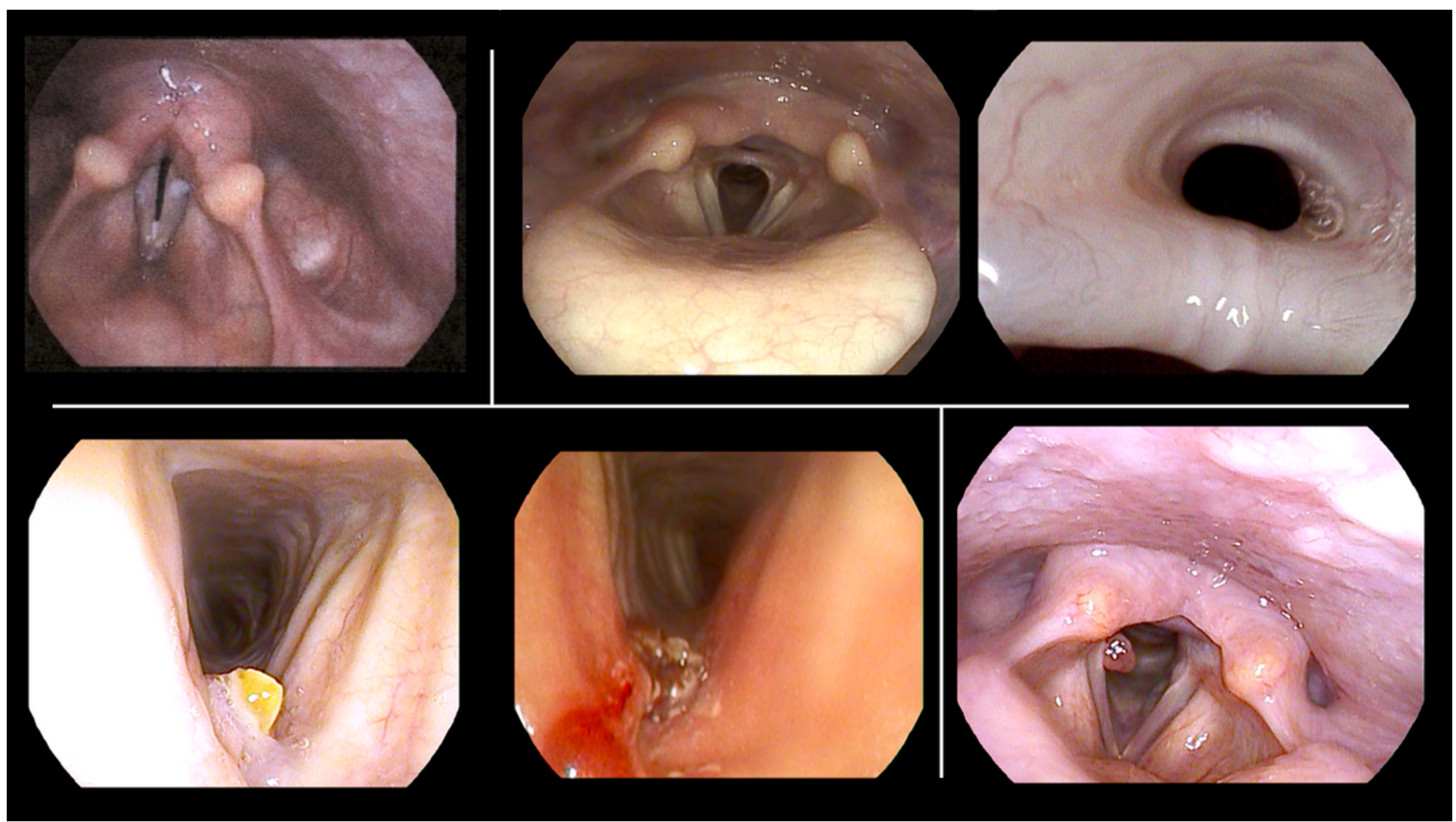

Figure 1

(clockwise from top left) bilateral vocal cord immobility - maximum abduction, posterior glottic scar, right vocal cord intubation granuloma, post tracheostomy A-frame deformity with displaced cartilage and granuloma - treated with blue laser 